\title{
Parking System Development Using Extreme Programming Method
}

Johannes Fernandes Andry, Gary Juliawan, Yosua Christian, Jeffry Leonardo, Nicolas

Faculty of Technology and Design

Universitas Bunda Muli

Jakarta, Indonesia

jandry@bundamulia.ac.id

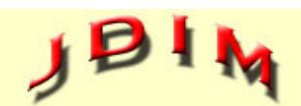

Journal of Digital Information Management garyjuliawan@gmail.com

yosuachristian02@gmail.com

jefryleonardo97@gmail.com

nicolassaputra9586@gmail.com
ABSTRACT: In developing cities such as in Jakarta, there are a lot of vehicle parking locations that still use conventional methods, which can harm drivers and also parking area owners alike, the process is slow and unsafe, making many people around feel afraid to use parking locations that are still conventional, the conventional parking lots in Jakarta is too many, sometimes also make people have no other choice but to use unsecured parking lots, theft is the main factor that is difficult to avoid, especially in developing countries like Indonesia, which are not safe, and the location of the parking lot that is very open, makes a lot of opportunities which of course can be used by thieves or irresponsible people. Not only thieves, drivers who do not want to pay for parking, are also a problem for owners of parking lots. With the problems of these users, we plan to make modular parking applications that can be installed easily and cheaply, but because our group is not so large, there are several challenges that we face, such as time and requirements that can increase later, with thus we plan to make this parking application using the Extreme Programming method, which is possible and very suitable for the problems that our group is facing. The use of Extreme Programming turned out to be very helpful, and can also produce an application that matches the existing user stories.
Subject Categories and Descriptors K.6 [Management of Computing and Information Systems]; Performance and usage measurement:

General Terms: SDLC, Parking

Keywords: XP, New Parking System, Traditional Parking, Microsoft Visual Basic, Microsoft Access

Received: 14 April 2018, Revised 28 May 2018, Accepted 9 June 2018

DOI: $10.6025 / \mathrm{jdim} / 2018 / 16 / 6 / 279-288$

\section{Introduction}

Parking lots in most cities in developing countries use manual systems that use human power to record data in and out of parking, and receive parking payments. Parking systems are a major requirement in various places such as buildings, malls, etc. Parking lots is one of the important things in urban areas in developing countries, both in local and strategic planning [1]. Cities around the world are also struggling to revitalize parking spaces in their city center, especially those that use roadside as parking lots [2]. In general, parking systems are always 
underestimated and not so important, and are only managed manually or rearranged when problems arise [3]. But in fact, a good parking system in a parking lot will increase the safety of the vehicle, and the overall progress of parking in a parking lot in an urban area.

The traditional parking process, still using paper and a parking guard who is tasked to record the entry and exit of vehicles and receive payments, on large parking lots, the need for a parking guard will increase, and security in the parking lot is reduced. Conventional parking systems are very dependent on human relations with parking lots and drivers directly from the beginning of the process. This method causes waste of human power if the parking lot is very wide. This parking lot relies on the Human to Human Interaction $(\mathrm{HHI})$ in the entire parking process which is inefficient and slow [4]. Roadside parking can only meet a small portion of the overall parking demand, and as a result, regulations on roadside parking are highly regulated by the government so that drivers prefer the location or parking zone provided by local zoning procedures, which are isolated, all or in part, and much safer [5]. As stated by Greg Masdren. Therefore, the presence of many parking lots seems to have a close relationship with the increase in private vehicle ownership and use [6].

The slowness of the conventional parking process provides some of the adverse effects that can be caused by it, the safety of the parked vehicle is one of the adverse impacts of the conventional parking process, on large conventional parking lots. Conventional parking systems do not have a system that can monitor the parking and parking lots are monitored by a limited number of security guards [7]. The availability of a good parking lot can also be one of the factors that influence the decision to drive when we know the availability of parking space at the place we are going to [8]. In general, people will find out in advance the condition of the parking lot somewhere before deciding to use a private vehicle, with the reason that it is not bothered by a parking system that is not good and unsafe, or the unavailability of parking spaces that can be used. Then, in the conventional parking method, everyone is required to pay for parking, no matter how often the person uses the parking lot or not, it will be very detrimental to the workers who desperately need the parking lot. The study, created by Daniel Baldwin Hess, describes the effect of parking costs on influencing travel behavior by employees to park at work. Research finds that employees are more likely to drive using private vehicles that are more comfortable when going to work when parking costs are cheaper or free [9].

The creation of a new parking system allows a parking lot to improve the security, provide vehicle reports and cash income in the selected period, and also has a member parking feature that will reduce the burden on drivers who often use parking space for a long duration. Many cities in several countries, nowadays, use roads, or parking lots that are free or underpriced [10], which can cause problems if applied continuously, for example, the use of parking spaces on the side of the road can hamper the net traffic in the area, and parking locations that are free or too cheap, do not have many guards and consequently security is a major problem. Technological progress is a positive thing that we are experiencing right now and this has brought about a considerable change in the traditional parking system [11] because it provides a good solution in terms of parking that can be used by many parking locations who need it, and also parking software that will greatly help monitor the use of parking lots, and the income earned from the parking lot. It is undeniable, that the parking lot is now like a business area itself, the lack of parking lots, especially parking lots that have a good and safe system, are also a major problem. The existence of a parking location is very important, especially when someone uses a vehicle to travel to a work location or entertainment location, and they do not use drivers who can drop them and leave them to be picked up later [5] but on this topic we will not discussing the lack of parking locations, we only provide solutions to parking locations that still use traditional methods.

Research that has been done in Europe results in the incidence of theft of goods on vehicles or vehicles itself usually occur in unsafe parking areas [12], [13]. From the statement, the driver will later avoid the use of parking locations that are not safe or do not have a system, and prefer to use a safer parking location, even if they are charged more. Security is one of the main goals of this parking system, parking locations that will use our system, must be closed, and only have an entrance or exit which is limited by an automatic electronic board that prevents the driver from leaving illegally, so as to reduce criminal crime, or for drivers who want to cheat on the system. Parking lot is only a land that are use by vehicles, the number of parking slots in a parking area and the configuration is very much related to the value of land in the area, the size of the economy owned by the landowner and the most important is the availability of technological support in the parking area [6]. Drivers can use any vehicle ranging from motorcycles, cars and trucks. this system provides benefits in time and pricing issues, users use less time to enter / exit the parking area [14] because of the new parking system that drivers use.

In designing this parking program we use the SDLC method which we think is the most suitable for the size of the team, and the project that we will work on, the agile methodology has a very important impact on the development of a system or program in recent years, especially this parking program [15].

In this project we use Extreme Programming, Extreme Programming is a software development methodology that is useful for improving the quality of software that is being created and quickly incorporating new needs from customers [16]. The commonly used software methodologies such as Waterfall, Vee-Method, and Rational Unified Process (RUP) are traditional or old- 
fashioned software development methods and now Extreme Programming has been classified as a top-class methodology [17]. Therefore, we use the Extreme Programming method to develop this parking system.

Based on this idea, we will create a secure parking application, and have information and features that are easy to use and certainly useful for parking lots that still use traditional methods, we will explain the development in this parking system, using the Extreme Programming methodology, the author also will provide the planning stages that we have done, and the results of what has been done.

\section{Literature Review}

\subsection{Parking System}

Parking systems are needed especially in large cities that are densely populated and many people who use private vehicles, problems that arise due to poor parking systems, will have a very bad impact on the city. Parking is a condition where the vehicle is at a stationary point without the driver, and is placed in a vehicle storage area or called a parking lot [5]. There are many different parking systems in the world, in this parking system, we are looking for ways to make parking systems that are easy to use and will be implemented in parking areas in Jakarta that are still not computerized.

\subsection{Software Development Life Cycle}

Software Development Life Cycle (SDLC) is used with the aim of producing a quality system that meets user requirements, making work more effective and efficient at the development stage of an information system project. The software development methodology that is almost used by all IT companies in the world is the Software Development Lifecycle. Waterfall Method, spiral method, incremental method, rational unified process (RUP), rapid application development (RAD), agile software development, and rapid prototyping are some of the SDLC methods which have been successful and tested [18]. In the IT and Software industries, projects with various sizes and weights are developed using many principles and approaches in software design. The use of SDLC is used for the development of software projects with different and regular development phases such as analysis phase, design phase, programming phase, testing phase and maintenance phase at the end of the project [19]. Selecting the right SDLC method can affect the performance of the team and also the time used in developing a software.

\subsection{Extreme Programming}

Extreme Programming is one of the most popular Agile Process Model. Extreme Programming has proven to be very successful in many companies of various sizes and industries throughout the world. Extreme Programming emphasizes teamwork. Extreme Programming implements a work environment that is simple but effective and allows the team to be very productive in project execution. Extreme Programming is made to overcome uncertainty in the development of a project and emphasizes more on social relationships between teams and users or clients. Extreme Programming is also formed to reduce risks to the project because of its dynamic work processes and increase the likelihood of success on the project [20]. Extreme programming also has four stages that must be passed when starting and working on a project, namely: Coding, Testing, Listening, Designing, and starting again from the coding stage, until finally doing a small release (increment) or full release.

\section{Research Methodology}

Extreme Programming is an SDLC model included in the agile method introduced by Kent Beck. According to Kent Beck "Extreme Programming (XP) is a method of software development that is fast, efficient, low risk, flexible, predictable, scientific, and fun.". Extreme Programming has a focus on situations involving small teams. The majority of Extreme Programming requires team work, for example asking other people or partners or other team members to review your code [21][21]. Extreme Programming tends to use an Object-Oriented approach. The stages that must be passed include: Planning, Design, Coding, and Testing. Extreme Programming is designed to complete the project in accordance with the Requirements but has a small to medium work team. Extreme Programming is the most widely used agile method and is a very well-known approach. Extreme Programming is based on five values that must be possessed in the work environment as well as team members [16]:

- Simplicity, Making things as simple as possible but still in accordance with the user requirements that have been set, don't overdo it.

- Communication, The relationship between communication between the team and the end user or client is needed to achieve the goals according to their needs.

- Feedback, For customer satisfaction, the involvement of users or customers in the execution of the project is needed for the smooth running of the project.

- Respect, All team members must be able to respect themselves, others, and also the projects that are done.

- Bravery, Developers must have the courage and confidence to bring quality results.

Extreme programming is made to handle changes that usually occur during software development, take a look at Figure 1, XP Development Life Cycle. In addition, Extreme Programming is also made to overcome various requirements that are not clear from the user or client. As a methodology for developing software, Extreme Programming certainly has a life cycle. The life cycle of 


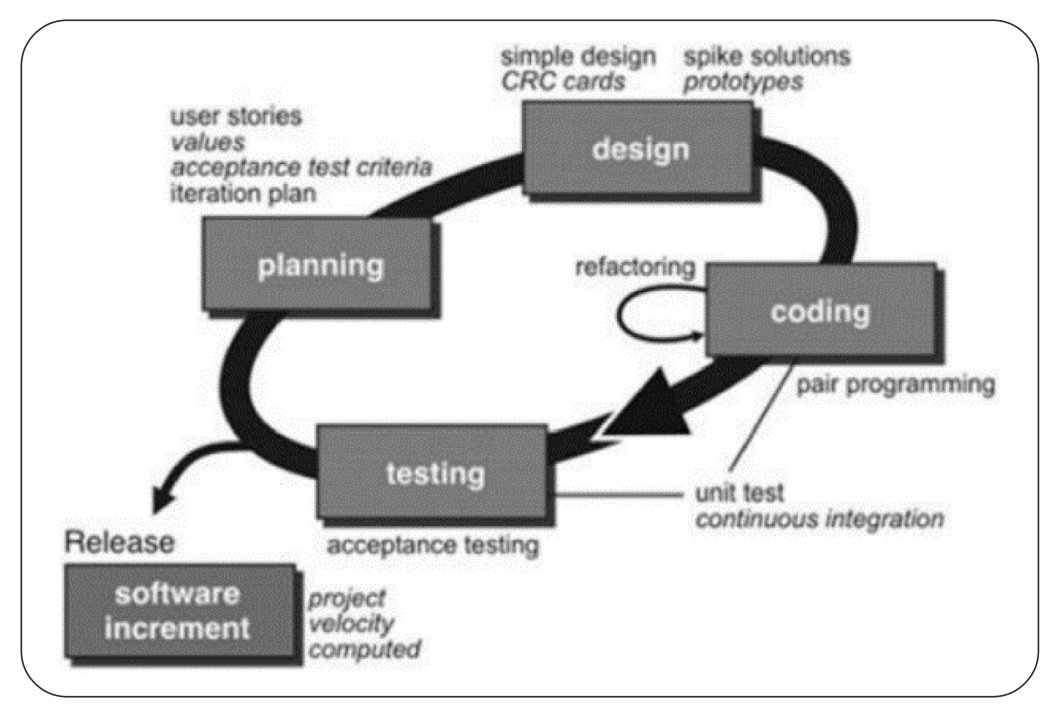

Figure 1. XP Development Life Cycle [22]

extreme programming has five phases, namely:

- Exploration Phase

- Planning Phase

- Iteration to Release Phase

- Productionizing phase

- Maintenance Phase

Extreme Programming in its use, has several stages in developing a software, this stage is the main backbone that makes Extreme Programming. Stages in Etreme Programming, namely:

- Planning, Planning activities begin by forming user stories. The XP team member then assesses each story and determines the cost and is measured in the development week.

The customer and team work together to decide how the next story group for release (the next software increment) will be built by the team. If the commitment has been made, the team will build the stories by:

All stories are implemented immediately (in a few weeks)

1. Story with the highest value will be removed from the schedule and implemented first.

2. Stories with the highest risk will be implemented first. After the first project was released and received, XP team calculated the speed of the project. During development, customers can add stories, change values, divide stories or delete them.

- Design, Extreme Programming uses a CRC card, to recognize and manage object oriented classes that correspond to software increments. CRC cards or called Class - Responsibility - Collaboration are brainstorming tools used in object oriented software design.

- Coding, Extreme Programming recommends that two people work together on a workstation computer to create code from one story (pair programming), to provide real time problem solving and guarantee real time quality. After pair programming is complete, the code is integrated with other work (continuous integration).

- Testing, Unit tests that have been made must be implemented using a framework and arranged into universal testing suites, system integration and validation can be done every day. Customer test (acceptance test) is performed by the customer and focuses on the overall features and functional systems. Acceptance tests are obtained from customer stories that have been implemented as part of software release.

In object oriented development within Extreme Programming, we can use CRC to design the framework on Extreme Programming, CRC or Class - Responsibility - Collaboration are brainstorming tools used in object oriented software design [22]. See Figure 2, Class Responsibilities Collaborator.

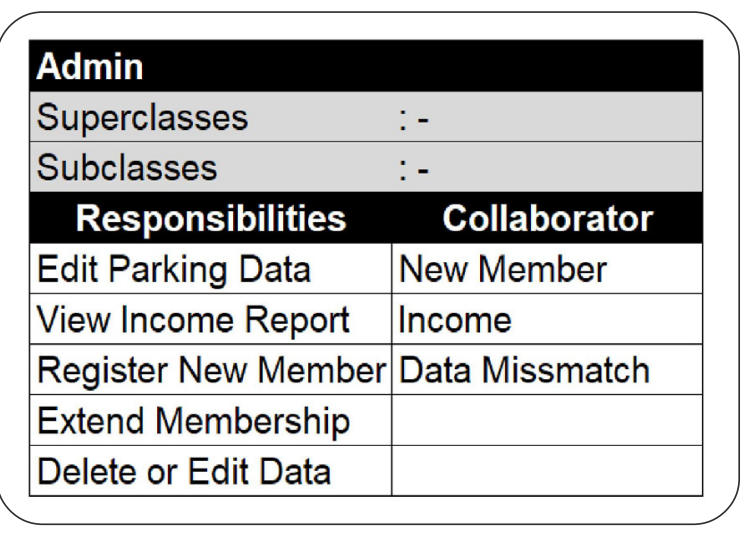

Figure 2. Class Responsibilities Collaborator 


\section{Proposed Parking Application}

With the problems discussed in the previous introduction, we provide solutions to conventional parking owners, by making parking applications that are easily implemented in conventional parking areas or vacant land in Jakarta, although there are several requirements that will be needed, but by implementing this parking application, it will provide security in the parking lot, ease in the parking process, take care and check vehicle data or report cash income generated by parking lots. This application was developed using Visual Basic, and has an easy-to-use user interface that is understandable and easy to use by employees in parking lots.

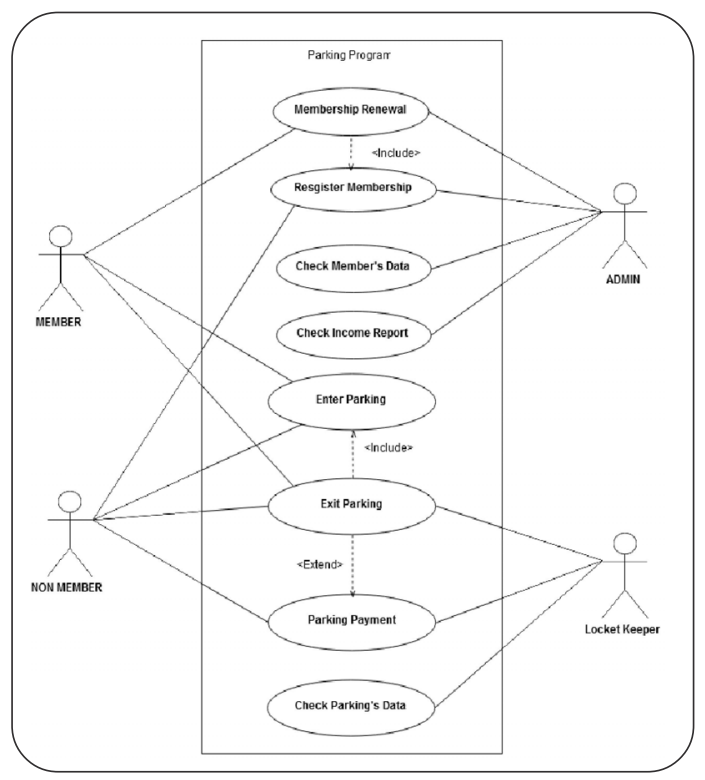

Figure 3. Proposed Parking Application Use Case
The use case of this application, see Figure 3, Proposed Parking Application Use Case, is also not complicated, in the implementation later, there will be four actors who have their respective roles, the employee unit is divided into two people, namely admin and also the counter keeper who will check whether the vehicle and the tickets used to exit the parking area is in accordance with when the driver enters the parking area, it requires human verification because it is a security problem that is better not done by the engine, here Admin acts as a person who is in charge of checking parking data, member data, and also cash income reports that have been get, Admin is also in charge of helping a Member and Non-Member who wants to register or extend the validity period of the membership in the parking area. ANon-Member who often uses parking lots will be given the ability to make himself a member with the requirement to pay a monthly fee paid to the Admin, and later the Admin will provide a Member sign card parking in that area which can be used to enter and leave the parking area for free.

There is a very significant difference from the old parking process and the parking process using this application, the difference is seen in the process of entering and also leaving the parking area, where conventional parking is still very dependent on the parking lot guards who guard the area. There are times when the parking lot is wide enough, the number of workers in the parking lot will not be enough, and can have an impact on "ineffective employee management". Reports using the writing system that is applied by employees are also prone to fraud and invalid data, which will certainly harm the parking lot owner. Here are the significant differences between the two parking processes, take a look at Figure 4, Difference Between Old Parking Method and New Proposed Method.

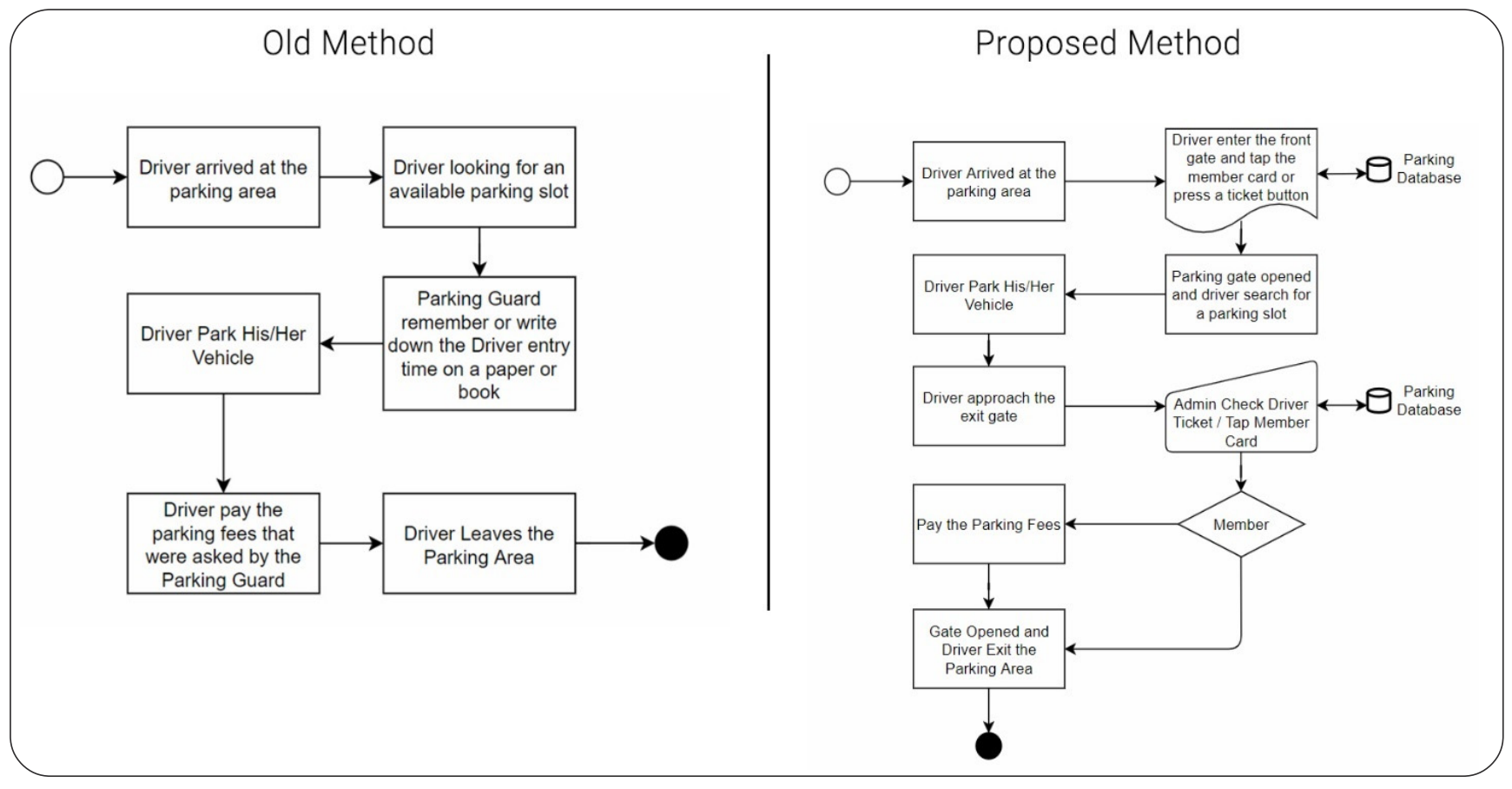

Figure 4. Difference Between Old Parking Method and New Proposed Method 


\section{How Security Will Be Better Using Proposed Parking Application}

Security is the most important thing in parking lots, losses due to lack of security can affect the driver and also the owner of the parking lot itself. Thus, our parking application emphasizes security to avoid theft of vehicles, and also drivers who do not carry out their obligations to pay for the parking service. The vehicle thieves, usually using two factors that support him in carrying out criminal actions, namely the location that supports and also the lack of protection in the area [13]. Making a closed parking area and checking parking data in the parking exit, will make a vehicle thief cannot bring a vehicle that is not his from the parking area. But there are some things that must be added for the sake of more security in parking lots, such as: CCTV cameras in every corner of the parking lot, and also guards who monitor the parking lot 24/7, even though the two things are not mandatory, but it is better if the parking owners can provide extra security which will have a good impact on the parking lot itself.

In the old system, drivers can search for gaps out of the parking lot without having to pay for parking, because parking area guards are not likely to be in the area for 24 hours, so there are some gaps that can be used by drivers which ultimately harm the parking lot owner. We cannot prevent cheating on employees and parking users, but we can limit it by having a new parking system that is safer and minimizes fraud. In the new system, drivers and employees are faced with the use of applications that are connected to the database so that employees cannot manipulate data from parked vehicles and also parking users cannot get out without paying their obligations.

\section{Parking Area Prerequisite}

Making this parking application, will not be able to run perfectly without the requirement that must be used so that the system can run properly, there are some requirement that are essential prerequisites, for the sake of running a new system in the parking lot that want to be changed, the prerequisites are, namely:

\section{Parking Gates}

The parking gates are used in the entrance and exit to the parking area, this gate are useful for holding drivers who want to enter or leave the parking area without taking a ticket or paying on the exit, the parking gate at the entrance, will automatically open after the driver has placed the card or pressed button to get a parking ticket

\section{Exit Parking Booth}

In the parking exit, there must be an officer who helps the driver when he wants to get out of the parking area, the officer will stay inside the booth while waiting for the driver who wants to leave, this officer will receive payment and also open the exit gate for drivers who have paid or using the member card after using the parking lot.

\section{Admin Office}

For drivers who wish to register as parking members, the driver must go to the Admin Office located near the parking lot, and request a member card to be made as a sign that the driver does not have to pay a parking fee within the specified time period.

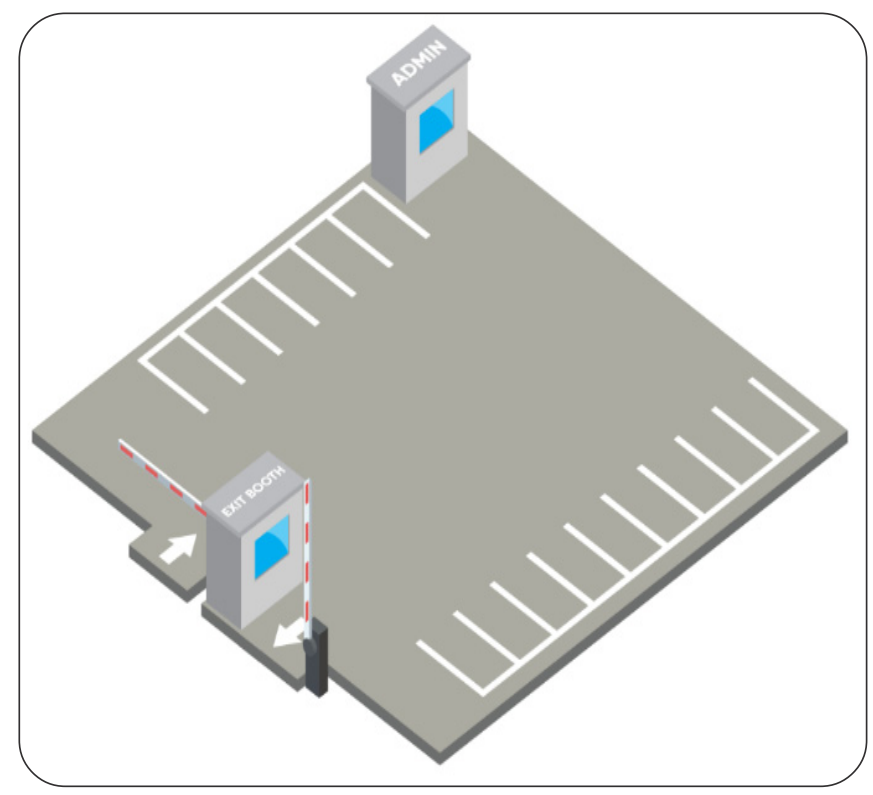

Figure 5. Parking Area Sample With All Prerequisite Applied

But its not limited by only those three prerequisite, there are also other thing, such as: a computer for admin and on the exit gate booth, computer server, and card reader.

The use of these prerequisites is only need to be prepared at the beginning of the installation of the new parking systems. To see more clearly how the parking area will look with all the prerequisites, can be seen in Figure 5, Parking Area Sample With All Prerequisite Applied.

The Figure 5, Parking Area Sample With All Prerequisite Applied, is just a small example of how to use these three prerequisites when implemented. This system can be expanded to accommodate the increasing number of parking vehicles by adding or expanding parking lots later [7]. So that the entire parking area can be more modular.

\section{Strategy of Developing Parking Application with Extreme Programming}

We are a group of four people, of which the scale is very small compared to the project done, thus we use Extreme Programming, here are the stages that our group is doing together so that the creation of this application can be completed:

\subsection{Planning Phase}

In the planning phase, at first we are going to create user stories, and determine the requirements needed based on the user stories, we did our planning of creating the 
entire system, we also plan our testing phase, and how we should launch the test which uses the User Acceptance Testing method. We do stories creation which will determine which feature will be chosen and be implemented first. From the vast ranges of available user stories, we create a process based on the core value of Extreme Programming, which is simplicity, we chose the most important user stories first and create a list of requirements based of those user stories, these are the user stories which we have chosen, look at Figure. 6, Selected User Stories. using User Acceptance Testing, the use of User Acceptance Testing must be in accordance with some problems and requirements obtained from the planning stage with user stories. The results of the testing phase are reported to the User Acceptance Testing Report whose results can be summed up into two tables.

Take a look at Table 1, Defect Analysis, In defect analysis, this report shows the number of bugs that are resolved or closed at each level of severity, and how they are resolved, or not resolved at all, this defect report is needed to see

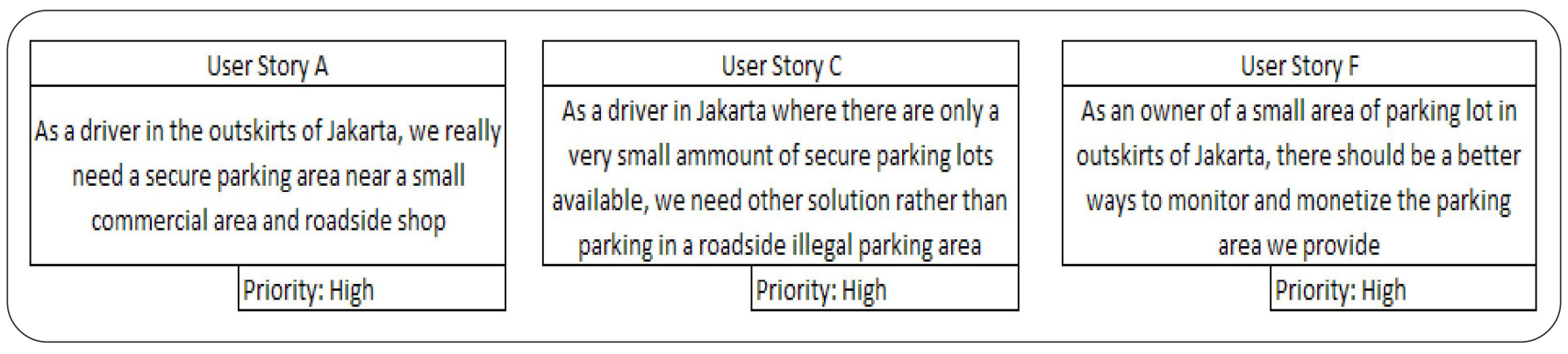

Figure 6. Selected User Stories

\subsection{Design Phase}

In the design phase we created the CRC cards or called Class - Responsibility - Collaboration, which will greatly help our group focus on the objects that will be developed, there are some CRC cards that we created and one of them belongs to the Admin, which can be seen in Figure 3 , Class Responsibilities Collaborator. After creating the CRC, we started making wireframe, our group of four people was divided into two groups first, namely the wireframe maker group and also the design, and the group for development with the pair programming method, the group division was used to minimize the time wasted due to team members waiting for each other to complete the work, thus, each CRC card that has been created, is continued by making a display that has a correlation with the CRC card, and is immediately given to the team development to be made together with pair programming.

\subsection{Coding or Development Phase}

It turns out that the coding phase has a longer time than the design phase, after the design phase is complete, the two people who are in the design team become a team that does development or coding, but everyone still does it together to run it in pair programming, which the uses of Pair programming in Extreme Programming is expected to minimize errors and bugs in the testing phase or later phases (Sharma \& Hasteer, 2016). The application was made by using Visual Basic programming language, developed by using Visual Studio 2013, and used Microsoft Access database that aims to make the database more accessible to the parking lot owner later.

\subsection{Testing Phase}

Testing phase is done to find out the errors and bugs that occur in the application, the testing phase is done by how the bugs and errors found during the testing phase.

\begin{tabular}{|l|l|l|l|l|}
\hline Resolution & Not Severe & Quite Severe & Severe & Sub Total \\
\hline By Design & 0 & 0 & 0 & 0 \\
\hline By Code & 1 & 2 & 1 & 4 \\
\hline Postponed & 0 & 0 & 0 & 0 \\
\hline Error & 0 & 0 & 0 & 0 \\
\hline Total & 1 & 2 & 1 & 4 \\
\hline
\end{tabular}

Table 1. Defect Analysis

Take a look at Table 2, Test Case Analysis, In Test Case Analysis, this report shows the number of test cases that have passed, failed, or have not been tested, this report is needed to see how far the application performance has been made and how many failures were found and have not been corrected during the testing phase.

\subsection{Release and Implementation}

After the testing and creation phase is complete, the application will be released and given to the parking lot owner incrementally, while accommodating and using other user stories to improve and continue to develop this application to be better when used in the field, according to user stories and requirements in the future which will come. The results of the application are in the form of a file that can be executed and run on the desktop that is owned by the Admin or the gate keeper later, and integrated with various tools that are the prerequisites that we have mentioned before. The application that has been created can be seen as follows, see Figure 7, Parking Application Main Screen. 


\begin{tabular}{|l|l|l|l|l|}
\hline Section & Test Case & Not Tested & Fail & Pass \\
\hline Login & 4 & 0 & 0 & 4 \\
\hline Main Menu & 10 & 0 & 0 & 10 \\
\hline Parking Entry & 3 & 0 & 0 & 3 \\
\hline Parking Entry Member & 6 & 0 & 0 & 6 \\
\hline Parking Entry Non-Member & 5 & 0 & 1 & 4 \\
\hline Parking Exit & 3 & 0 & 0 & 3 \\
\hline Parking Exit Member & 6 & 0 & 0 & 6 \\
\hline Parking Exit Non-Member & 55 & 0 & 0 & 5 \\
\hline Membership Registration & 11 & 0 & 2 & 9 \\
\hline Membership Validity Period Extend & 6 & 0 & 0 & 6 \\
\hline Parking Data Check & 29 & 0 & 0 & 29 \\
\hline Parking Member Check & 14 & 0 & 1 & 13 \\
\hline Parking Income Cash Flow & 7 & 0 & 0 & 7 \\
\hline Total & 109 & 0 & 4 & 105 \\
\hline
\end{tabular}

Table 2. Test Case Analysis

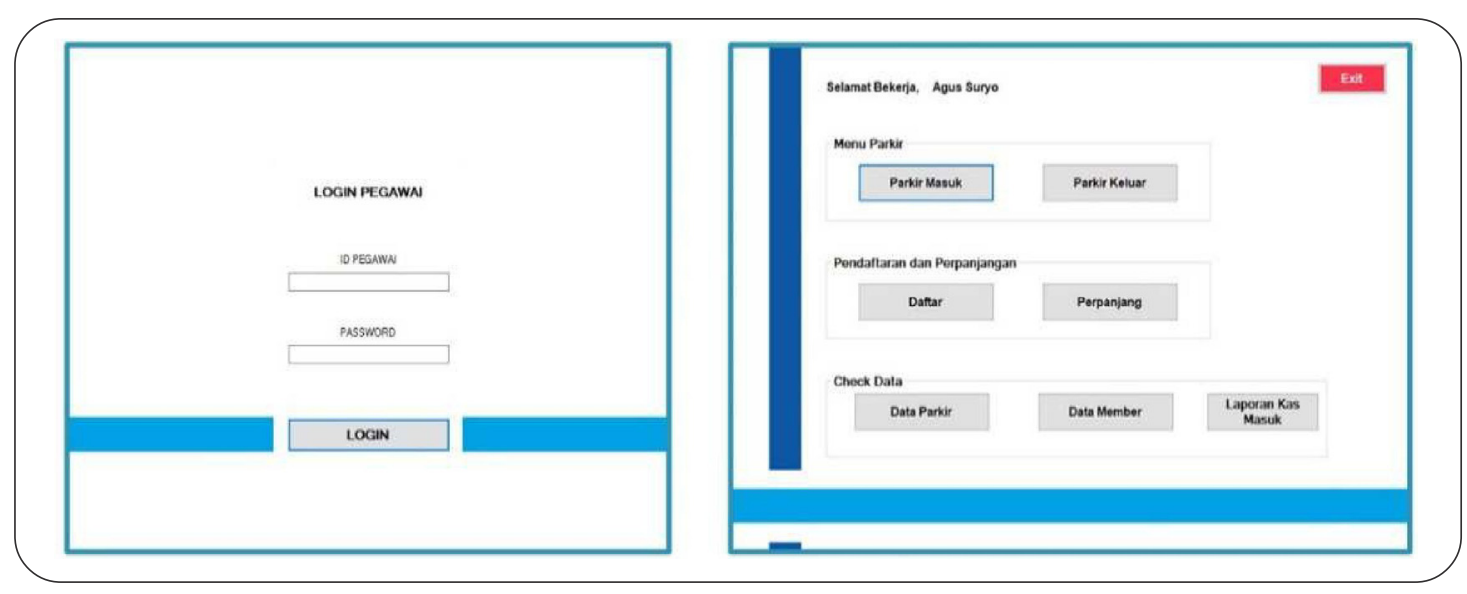

Figure 7. Parking Application Main Screen

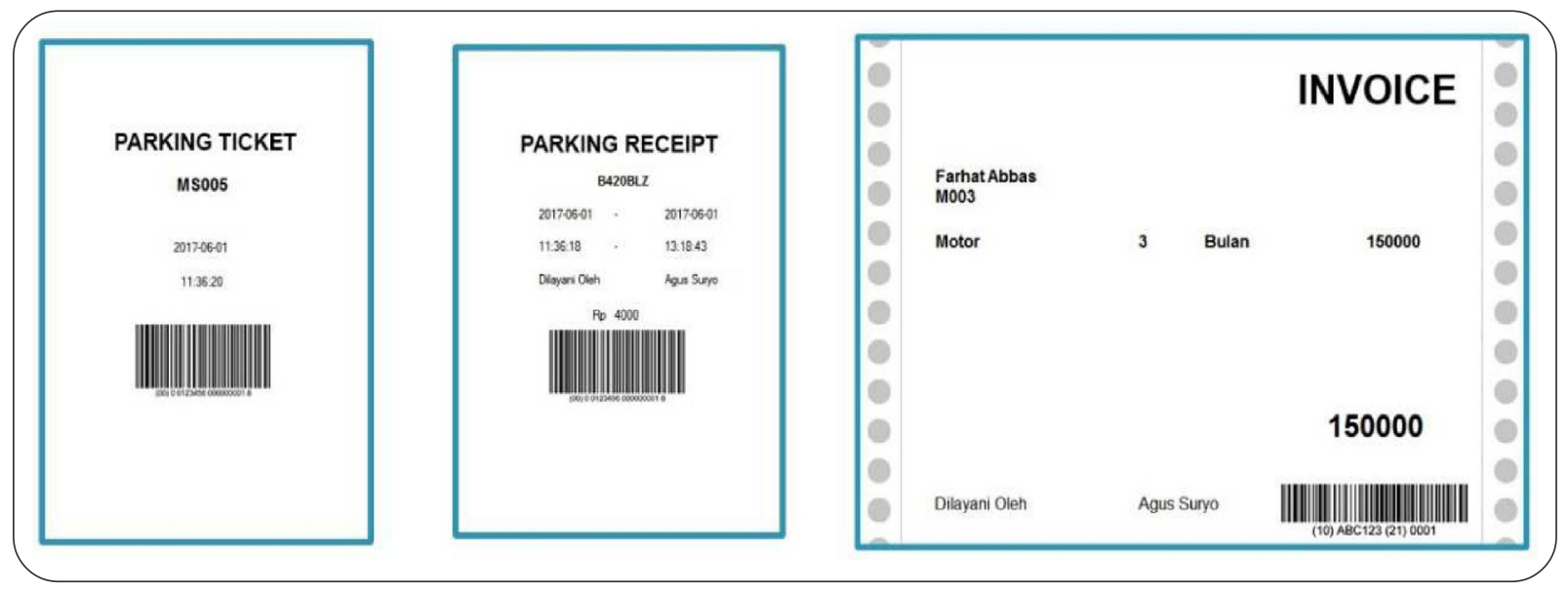

Figure 8. Parking Ticket, Parking Receipt, and Membership Re-Subscribe Invoice 
As can be seen in Figure 7, Parking Application Main Screen, are some of the main displays of the parking application that we made, the application has a variety of functions that have been created in such a way that is easy to operate by the Admin or the parking booth guard. In addition to the appearance of the application, there are also several displays of the ticket issued by the application, see Figure 8, Parking Ticket, Parking Receipt, and Membership Re-Subscribe Invoice.

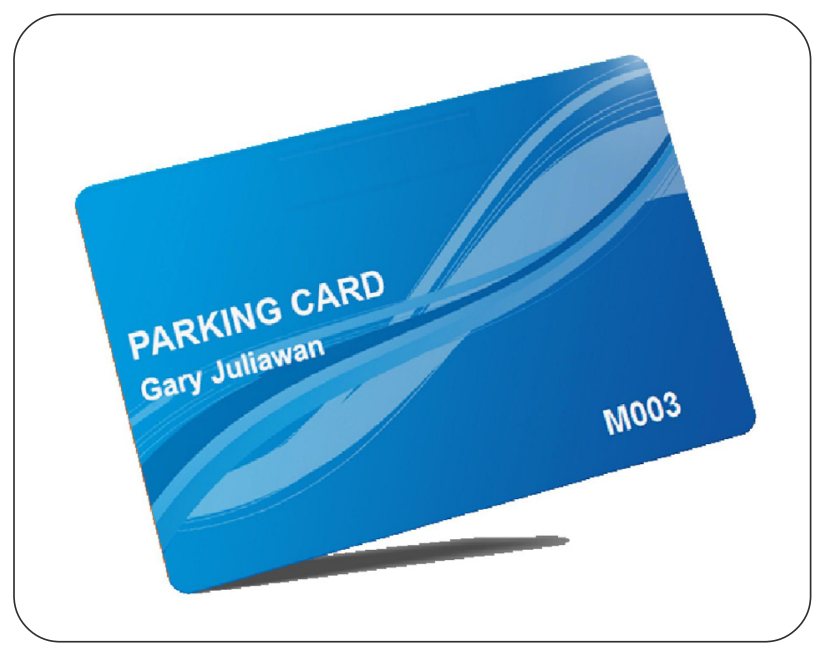

Figure 9. Parking Membership Card

The application can also fill the member card with data, which the driver can use to enter and exit the parking area without having to pay parking fees for a certain period, the card will be used when the driver enters and exits the parking area, instead of the parking ticket and parking receipt, the shape of the card can be seen in Figure 9, Parking Membership Card.

\section{Conclusion}

This parking application can help many parking areas in Jakarta to overcome some problems that can happen in the parking area with a parking system that is all computerized, so parking monitoring activities and vehicle data collection can all be done more easily and more effectively because almost all activities are done automatically by the computer and only requires humans as supporters so that the parking process will also be safer.

Our group managed to create a parking application which in our opinion and also users can help the parking process in the Jakarta area and the outskirts of Jakarta to be better and safer for drivers and landowners of the parking area. The use of Extreme Programming really helps our small group to complete this project quickly and can also adapt to the additional requirements in the future. Based on this experience, our group believes that making this parking application can continue to be developed and other modules can be added that can improve the parking system later.

\section{References}

[1] Young, W. (2007). Handbook of Transport Modelling Modelling Parking Article information/ : About Emerald www.emeraldinsight.com.

[2] Marshall, W. E. (2014). On-street parking, Transp. Sustain., vol. 5, p. 361-380.

[3] Bates, J. (2014). Parking Demand Article information.

[4] Shaikh, F., Nikhilkumar, B. S., Kulkarni, O., Jadhav, P., Bandarkar, S. (2015). A Survey on 'Smart Parking' System, J. Clean. Prod., 11(2), p. 9933-9939.

[5] Ferguson, E. (2005). Access to Destinations Parking and Accessibility Article information/: About Emerald www.emeraldinsight.com.

[6] Marsden, G. (2014). Parking Policy Article information.

[7] Baglane, S. B., Kulkarni, M. S., Raut, S. S. (2014). Parking Management System, Transp. Sustain., vol. 5, p. 157-184.

[8] Shiftan, Y., Burd-Eden, R. (2001). Modeling Response to Parking Policy, Transportation Research Record Journal of the Transportation Research Board, 1765 (01), p. 2734.

[9] Hess, D. (2001). Effect of Free Parking on Commuter Mode Choice: Evidence from Travel Diary Data, TTransportation Research Record, 1753 (1), p. 35-42.

[10] Manville, M. (2014). Parking Pricing Article information.

[11] Polycarpou, E., Lambrinos, L., Protopapadakis, E. (2013). Smart parking solutions for urban areas, 2013 IEEE 14th Int. Symp. a World Wireless, Mob. Multimed. Networks, WoWMoM 2013.

[12] Ekwall, D., Lantz, B. (2015). Cargo theft at non-secure parking locations, International Journal of Retail \& Distribution Management, 43 (3), p. 204-220.

[13] Ekwall, D., Lantz, B. (2013). Seasonality of cargo theft at transport chain locations, International Journal of Physical Distribution \& Logistics Management, 43 (9), p. 728-746.

[14] Stankovski, S., Ostojic, G., Djukic, N., Tegeltija, S., Milojkovic, A. (2014). Bluetooth parking access control, Sens. Rev., 34 (3), p. 244-254.

[15] Ghani, I., Yasin, I. (2013). Software Security Engineering In Extreme Programming Methodology: A Systematic Literature, Science International, 25 (2), p. 215-221.

[16] Kolte, P., Bhujbale, T., Chaware, A. (2012). Web Portal Development using Extreme Programming Practices, International Conference on Recent Trends in Information Technology computer science, p. 32-37.

[17] Hameed, A. (2016). Software Development Lifecycle for Extreme Programming, International Journal of Information Technology and Electrical Engineering. ITEE, 
5 (1), p. 7-13.

[18] Bassil, Y. (2012). A Simulation Model for the Waterfall Software Development Life Cycle, International Journal of Engineering \& Technology, 2 (5), p. 2049-3444.

[19] Egwoh, A. Y., Nonyelum, O. F. (2017). A Software System Development Life Cycle Model for Improved Students Communication and Collaboration, International Journal of Computer Science and Engineering Survey, 8 (4) p. 1-10.
[20] Kamthan, P. (2007). Extreme Programming for Mobile Applications, p. 2007-2009.

[21] Agarwal, R., Umphress, D. (2008). Extreme programming for a single person team, Proceedings of the 46th Annual Southeast Regional Conference on XX ACM-SE 46, p. 82.

[22] Suryantara, I. G. N., Andry, J. F. (2018). Development of Medical Record With Extreme Programming SDLC, 5 (2) $47-53$. 